\title{
Modularize and Unite: Toward Creating a Functional Artificial Cell
}

\author{
Chen Wang ${ }^{\dagger}$, Junzhu Yang ${ }^{\dagger}$ and Yuan Lu* \\ Key Laboratory of Industrial Biocatalysis, Department of Chemical Engineering, Ministry of Education, Tsinghua University, Beijing, \\ China
}

An artificial cell is a simplified model of a living system, bringing breakthroughs into both basic life science and applied research. The bottom-up strategy instructs the construction of an artificial cell from nonliving materials, which could be complicated and interdisciplinary considering the inherent complexity of living cells. Although significant progress has been achieved in the past 2 decades, the area is still facing some problems, such as poor compatibility with complex bio-systems, instability, and low standardization of the construction method. In this review, we propose creating artificial cells through the integration of different functional modules. Furthermore, we divide the function requirements of an artificial cell into four essential parts (metabolism, energy

OPEN ACCESS

Edited by:

Allen Liu,

University of Michigan, United States

Reviewed by:

Cheemeng Tan,

University of California, Davis, United States

Siddharth Deshpande, Wageningen University and Research, Netherlands

${ }^{*}$ Correspondence: Yuan Lu yuanlu@tsinghua.edu.cn

${ }^{\text {t}}$ These authors have contributed equally to this work

Specialty section: This article was submitted to Biophysics,

a section of the journal Frontiers in Molecular Biosciences

Received: 23 September 2021 Accepted: 17 November 2021 Published: 29 November 2021

Citation:

Wang C, Yang J and Lu Y (2021) Modularize and Unite: Toward Creating a Functional Artificial Cell.

Front. Mol. Biosci. 8:781986. doi: $10.3389 /$ /fmolb.2021.781986 supplement, proliferation, and communication) and discuss the present researches. Then we propose that the compartment and the reestablishment of the communication system would be essential for the reasonable integration of functional modules. Although enormous challenges remain, the modular construction would facilitate the simplification and standardization of an artificial cell toward a natural living system. This function-based strategy would also broaden the application of artificial cells and represent the steps of imitating and surpassing nature.

Keywords: artificial cell, bottom-up construction, modularization, unity, function

\section{INTRODUCTION}

With the million years of development, biological cells have established a high structural hierarchy and complex metabolic networks. The complexity has greatly hindered our understandings of the basic principles or mechanisms of life activities, probably limiting the future applications of life science. Moreover, scientists have always wondered whether a living cell can be artificially achieved or even synthesized de novo. Some synthetic compartments with cell sizes have attracted considerable attention as cell mimics, for their potential to uncover the inherent complexity of life. These are socalled artificial cells, which can help us to further explore the origin of life (Szostak et al., 2001; Rasmussen et al., 2004; Yang et al., 2013) and provide breakthroughs into application fields, such as drug delivery (Zhang et al., 2008; Liu et al., 2009; Ashley et al., 2011), gene therapy (Chang, 2005; Prakash and Jones, 2005), biosensing, and diagnostic (Pardee et al., 2016; Jayaraman et al., 2018).

Generally, there are two strategies to construct an artificial cell, top-down and bottom-up. The top-down strategy usually starts with a living cell. By eliminating or replacing the genome of a living cell, it can reach a "minimal cell" with minimal gene information for survival (Gibson et al., 2010). However, this strategy might be limited to the inherent complexity of living cells themselves. The other strategy, bottom-up, aims to construct a cell-mimic by assembling from nonliving materials. As Richard Feynman declared, "What I cannot create, I do not understand." The bottom-up strategy can leave design space to customize artificial cells with unique properties, which indicates that it cannot 
only reconstruct a living cell, but also create an unnatural system to discover new possible life forms and develop new exciting applications.

The fundamental thinking to construct a bottom-up artificial cell can be summarized as the compartment of biochemistry networks, including gene replication, transcription, translation, metabolism, and signal transmission. The complicated reaction networks should be kept in a strictly organized and efficient state in a tiny space. Therefore, the compartment is a key process, as a cell mimic should not only be physically separated from the environment to form an independent individual but still keep in touch with the outside. Up to now, several materials have been applied to encapsulate the cell-free system. Lipids are most similar to the natural membrane, thus widely utilized to construct artificial cells (Noireaux and Libchaber, 2004; van Nies et al., 2018). Furthermore, other functional materials, such as polymers (Huang et al., 2013; Ugrinic et al., 2018), hydrogels (Park et al., 2009; Lai et al., 2019), and coacervates (Sokolova et al., 2013; Dora Tang et al., 2014), are also developed to meet new requirements. These compartments have provided a relatively stable interior and also enabled the communication between inside and outside (Shen et al., 2018; Lai et al., 2019).

As there is no clear and pervasive criterion for living, an artificial cell is usually synthesized to resemble one or more functions of a living cell and may differ from each other. Nonetheless, the ultimate goal is to reproduce cellular function and customize artificial cells based on personal application. The construction of bottom-up artificial cells has achieved significant progress since the 21 st century. Simple biological functions can be realized inside a confined environment, including but not limited to the protein synthesis (Noireaux et al., 2005; Park et al., 2009), photosynthesis (Lee et al., 2018; Berhanu et al., 2019), membrane proliferating and division (Matsuo et al., 2019), and signal transmission (Niederholtmeyer et al., 2018; Joesaar et al., 2019).

However, as natural cells are quite different from each other and capable of diverse life activities, it would be impossible to mimic every specific function. An effective strategy is to rebuild the functional networks by combining several basic blocks, just like Lego. In this case, people could create what they need through a standardized method. From the common ground of natural cells, the basic functions could be summarized into four aspects: substance metabolism, energy supplement, proliferation, and communication. Generally, the substance metabolism promotes dynamic communication among substrates, thus providing the material base for life. As most life activities are energy dissipative, it is crucial for the artificial cell to gain sufficient energy to support its functions. Another specific characteristic of a living system is the ability of proliferation, that is, to grow, copy themselves, and split. There seem to be three distinctive processes, but they should be considered as a whole for their equally critical efforts toward the subsequent generations. Moreover, an artificial cell should also have the ability to exchange information with and respond to the environment or other living systems. Based on the communication, it may adjust the internal activities, which paves the way for the adaptive evolution toward a real living system (Szostak et al., 2001). In the following context, we mainly focus on the latest development of these function modules, the basic

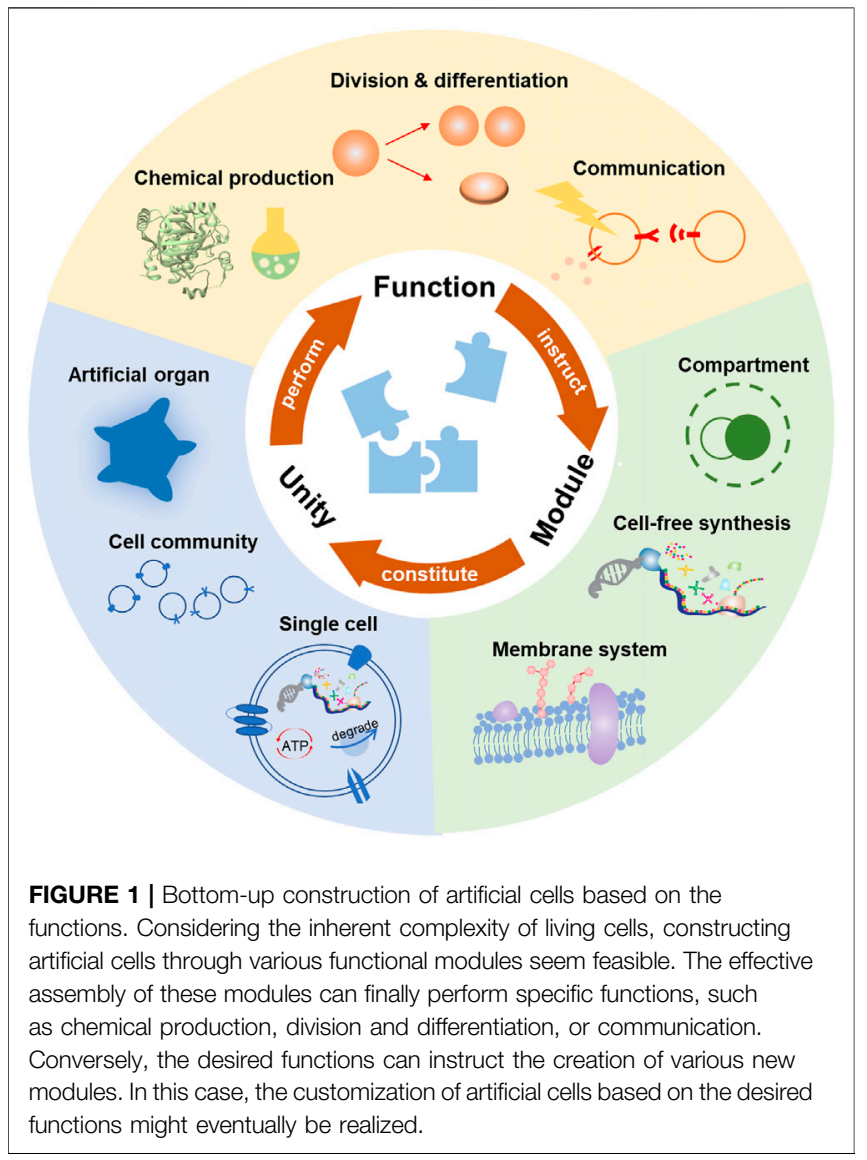

principles of construction, and their development in the future. Then we discuss their combination toward a complex artificial cell. Here we demonstrate that the unity should observe several disciplines to realize efficient synergistic behaviors. Through the integration of these four modules, one can realize the full complexity of a living cell in a methodical way or even customize the artificial cell with unnatural functions (Figure 1).

\section{MODULARIZATION}

\subsection{Substance Metabolism}

Metabolism describes the overall biochemical reactions in a living organism, which meets the essential material requirement for survival and provides conditions for advanced functions, such as communication. In this case, the construction of metabolism inside an artificial cell is significant and endows the tiny compartment with various functions as a living cell. Here we mainly focus on the substance conversion that happens in biological processes, such as the synthesis of macromolecules, and argue how to construct effective substance metabolism in an artificial cell (Figure 2, Substance metabolism).

\subsubsection{Cell-free Protein Synthesis System}

Synthesizing proteins is crucial for living cells, as these biomacromolecules take a significant role in almost all cellular 


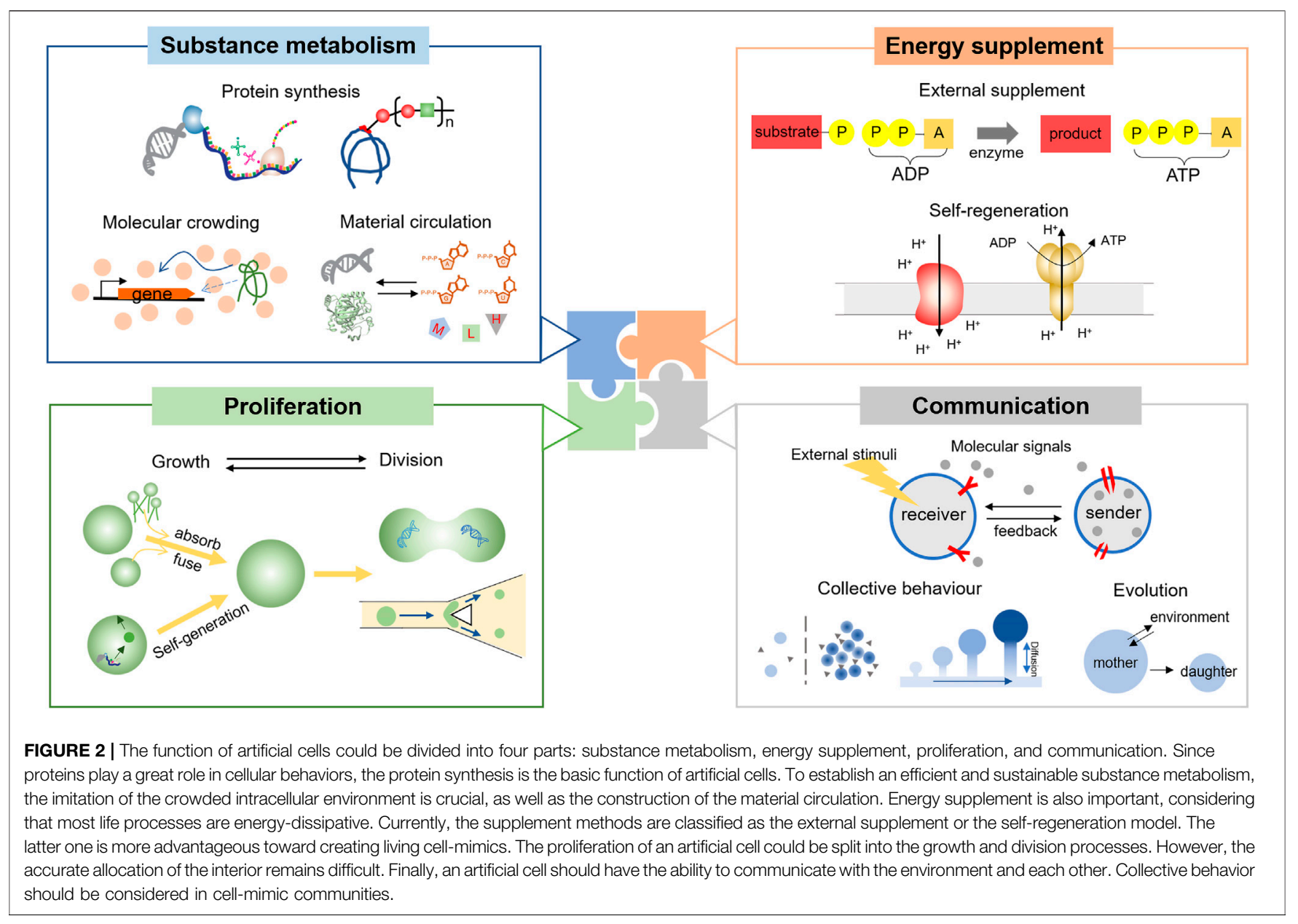

behaviors. They have complicated quaternary structures and can function as structural supports of organisms or various biocatalysts. Therefore, producing proteins on-demand in an independent and efficient way is fundamental for a biomimetic artificial cell. A cell-free protein synthesis (CFPS) system (Nirenberg and Matthaei, 1961) is an in vitro system, which enables transcription and translation processes outside cells. It simplifies the complex interactions in a living cell and only consists of the necessary elements for protein synthesis, such as gene templates, related enzymes, amino acids, salts, energy substrates, and cofactors. The principle behind CFPS is the biological central dogma, which refers to the transmission of genetic information from DNA to message RNA, and finally toward proteins. Due to the openness, simplicity, and operability, the CFPS system can provide an ideal platform for protein synthesis in artificial cells (Shin and Noireaux, 2012; Wu and Tan, 2014). Moreover, protein synthesis using recombinant elements (PURE) (Shimizu et al., 2001; Lavickova and Maerkl, 2019) system could completely customize the artificial cells, as its components are entirely purified and remain minimal but necessary for protein synthesis. For example, by adjusting substrates and enzymes in the PURE system, the metabolic pathways were controlled, and the detailed roles of ATPs were revealed in an ATP-producing artificial cell (Berhanu et al., 2019).
Although successfully producing model proteins like fluorescent proteins (Shin and Noireaux, 2012; Caschera and Noireaux, 2014), CFPS systems should be furtherly expanded to support the synthesis of complex and specific proteins. For example, membrane proteins are common proteins that perform crucial functions for cell survival (Almén et al., 2009). They could serve as enzymes, signal receptors, and transport machines. Therefore, the synthesis of membrane proteins has connected the boundary and the interior, thus facilitating the construction of artificial cells as an organic whole. Cell-free systems could provide an attractive platform to produce membrane proteins by adding surfactants or liposomes ( $\mathrm{Lu}$, 2017). These methods might still function in a membranebounded artificial cell. Several membrane proteins have been successfully synthesized and functioned in artificial cells, such as bacteriorhodopsins (Berhanu et al., 2019), cell division proteins FtsA (Furusato et al., 2018; Godino et al., 2020), and E. coli Min proteins (Godino et al., 2019). However, the correct assembling of de novo synthesized membrane proteins remains inefficient in artificial cells, partly due to the unclear integration mechanism of proteins into bio-membranes.

Another challenge is the post-translation modification of proteins in vitro. Most proteins require further modification after the translation process, such as glycosylation and 
phosphorylation, to become mature and undertake advanced physiological functions (Wang Y.-C. et al., 2014). However, these might be difficult or inefficient in vitro, as the explicit modification processes are often complicated, involving multiple metabolites (Kightlinger et al., 2019). Some countermeasures are the fabrication of cell extracts in CFPS from eukaryotic cells and the supplement of disulfide bond-forming enzymes or chaperones (Goerke and Swartz, 2008; Lu, 2017). Up to now, results have been achieved to introduce the complete enzyme systems or pathways for post-translation modifications in the cell-free solution (Kightlinger et al., 2019). Nevertheless, the ability of artificial cells to support modification processes needs to be improved, as they would be crucial in the construction of diverse metabolic pathways and other advanced cellular functions.

\subsubsection{Imitation of Intracellular Environment}

Intracellular homeostasis is important for normal metabolic activities. A significant difference between cells and solutions is the crowded environment inside the former. About $30 \%$ of the volume is occupied by macromolecules such as proteins, nucleic acids, and polysaccharides, whose concentration can reach $300-400 \mathrm{~g} / \mathrm{L}$ (Zhu et al., 2020), and even $500 \mathrm{~g} / \mathrm{L}$ in some compartments inside cells (Minton, 2015). The high concentration of macromolecules causes the so-called "macromolecular crowding" and brings significant effects to the interactions between participating biomolecules and the final metabolism (Rivas and Minton, 2016). First, the crowding environment can cause the excluded volume effect, which reduces the diffusion coefficients of both small and large molecules (Tan et al., 2013; Smith et al., 2017). Second, it also increases the equilibrium constants associated with macromolecules, probably due to the decrease in the total free energy of the solution after binding to molecules (Ellis, 2001). Moreover, the crowding effect can enhance the association of proteins, especially facilitating the folding or aggregation of proteins (Ellis, 2001; Bai et al., 2017). As bioreactions could be affected by both the diffusion process and molecule activities, the crowding effect on distinct bioreactions could be complicated with the increased concentration of macromolecules. In this case, creating a similar physiological medium inside an artificial cell deserves great attention.

Although the direct encapsulation could form a restricted interior, the concentration of macromolecules is usually not able to reach as high as in living cells (Minton, 2006). An intuitive strategy is to add inert crowding agents, such as poly (ethylene glycol) (PEG), dextran, and ficoll (van den Berg et al., 2017). These generally drift away from the major metabolism and might perform differently according to their species and concentrations (Ge et al., 2011). Therefore, this method might be limited to some extent. Considering the mismatching of diluted cell-free system with the large size of compartments, it would also be applicable to condense the cell-free reaction mixtures (Fujiwara and Nomura, 2013) and adjust the size of artificial cells through osmotic pressure regulation to create a more crowding internal environment. For example, monodisperse liposomes could shrink three orders of magnitudes to form crowded artificial cells (Deng et al., 2018). The interior solution finally reached about $272 \mathrm{~g} / \mathrm{L}$, which was close to the living cell.

Reconstitution of the crowded environment in an artificial cell is crucial in a broader sense. It causes the cytoplasm to be more similar to gels rather than solutions, and even leads to the lipidlipid phase separation (LLPS) to get membrane-free compartments (Ma et al., 2020). These intracellular structures are involved in diverse metabolism in both eukaryotes and prokaryotes (Wei et al., 2020), and have been proved to benefit the protein synthesis (Sokolova et al., 2013; Tang et al., 2015; Deng et al., 2018). Condensates inside artificial cells were successfully triggered through LLPS to conduct metabolic behaviors, such as enzyme catalysis (Deshpande et al., 2019a; Love et al., 2020), and study the potential coacervate-membrane interactions (Last et al., 2020). In a complicated metabolic network, these membrane-less organelles would ensure orderly biochemical reactions and provide valuable insights toward the real metabolism inside cells (Deshpande and Dekker, 2021). In this case, the crowded internal homeostasis and the local confinement would help construct an efficient and robust metabolic network inside an artificial cell.

\subsubsection{Complex Metabolism in Artificial Cells}

The encapsulation of one single enzymatic reaction would be relatively simple in the artificial cell. However, the complex bioreaction cascades or networks seem challenging because of the complicated processes and ambiguous mechanisms. Here, we propose that the recycling processes, which mainly refer to the circulation of metabolites and enzymes, should be carefully considered to construct complicated metabolism. In this case, more steady output and complex metabolic operation could be realized.

A robust and sustainable reaction network relies on stable conditions, which could be simplified as the continuous supply of substrates and elimination of products. This was primarily raised to prolong the life of cell-free protein synthesis, mainly through the selective permeability (Spirin et al., 1988) or anchor of the pore proteins onto membranes (Noireaux and Libchaber, 2004). After that, nanoliter-scale reactors, which could constantly exchange all molecules, were constructed to carry out diverse regulatory mechanisms (Niederholtmeyer et al., 2013). Meanwhile, the auto-regulated protein synthesis was achieved based on the on-chip DNA compartments (Karzbrun et al., 2014). These results proved the necessity of steady-state conditions for complex and continuous metabolic regulation. Recently, hydrogels with porous structures were applied to encapsulate the PURE system and support genetic oscillators through the continuous exchange of substrates and byproducts (Zhou et al., 2018; Lai et al., 2019). The circulation of materials could provide an opportunity for the construction and regulation of complicated metabolic networks.

Another crucial factor is the regeneration and digestion of biomolecules, such as nucleic acids and enzymes. As these biomolecules could lose activity during the reaction process, it is important for sustainable artificial cells to break them down and synthesize new substitutes. However, the de novo synthesis of 
original components is not a trivial task. On the one hand, most complex biomolecules are still hardly produced for the low efficiency or complicated assembly in vitro. On the other hand, as some functional enzymes prefer to function on membranes, the correct location is also essential. Up to now, significant progress has been made in reconstituting several vital biomolecules evolved in metabolism, including DNAs (van Nies et al., 2018; Libicher et al., 2020), ribosomes (Jewett et al., 2013; Shimojo et al., 2020), and tRNAs (Hibi et al., 2020). Recently, a partial self-regeneration artificial cell system capable of regenerating essential components was also constructed successfully (Lavickova et al., 2020). These results were mainly based on the minimal reaction demand. The next step would be substrate recycling in more complicated metabolic networks.

As for the digestion part, hydrolytic enzymes are commonly used in living cells for the digestion of biomolecules. However, their optimal $\mathrm{pH}$ is often at 4.5-5. To provide a proper degradation environment and prevent interference with other bioreactions, the encapsulation of hydrolytic enzymes as a lysosome-like module seems applicable. Actually, lysosomes inside eukaryotic cells consist of many hydrolytic enzymes, and the guidance of inactive biomolecules toward digestion is complicated and still under exploration (Bonam et al., 2019). Carreira et al. (2017) developed a type of lysosome-mimicking vesicles and discovered that the accumulation of sphingosines could cause the permeability and other biophysical changes of the membrane, which might facilitate the digestive function of lysosomes. The degradation of enzymes or other biomolecules is generally a necessary part of metabolism. Conclusively, more efforts should be made to construct an efficient recycling system inside an artificial cell or between artificial cells and the environment.

\subsection{Energy Supplement}

To maintain the complicated and sustainable metabolism as well as the homeostasis, an artificial cell should be supplied with sufficient energy. In a living cell, ATPs are the most common energetic substrate, whose generation and consumption are coupled with various bioreactions. Generally, there are three methods to produce ATPs in nature, including substrate-level phosphorylation, photo-phosphorylation, and oxidationphosphorylation. Inspired by these three processes, different strategies have been adopted to provide ATPs in a synthetic cellular system (Figure 2, Energy supplement).

\subsubsection{External Supplement}

The substrate-level phosphorylation refers to the direct coupling of energy-rich compounds with ATP production. Phosphate groups are extracted from the substrates and transferred to ADP or GDP to produce ATP or GTP. Because of the simplicity and easy-operating, this is widely applied in cell-free systems. Traditional high-energy substrates include phosphoenolpyruvate, creatine phosphate, and acetyl phosphate, which could support protein synthesis at the level of $\mathrm{g} / \mathrm{L}$ (Des Soye et al., 2018). However, the phosphate compounds could hamper the synthesis in a batch reaction, for their high costs, the accumulation of inorganic phosphate, and the pH change (Jewett and Swartz, 2004; Kim et al., 2007). In this case, glycolytic intermediates such as pyruvate (Jewett and Swartz, 2004), maltodextrin (Kim et al., 2011), and maltose (Caschera and Noireaux, 2014) were introduced for the recycling of inorganic phosphate, thus facilitating the ATP regeneration and improving the homeostasis of the cell-free system. Nonetheless, they might suffer from the inefficient utilization of the ATPs and other unexpected byproducts, as additional metabolic pathways were generally included (Caschera and Noireaux, 2014).

Another approach is to build a material exchange system. Through the continuous supply of energy and removal of harmful byproducts, artificial cells could reach a longer lifespan. For example, dialysis membranes were used to separate the cellfree system from the feeding buffer (Kim and Choi, 1996). Therefore, small molecules such as the energy substrates could diffuse across the membrane and support sustainable protein synthesis. Furthermore, pore-forming proteins were also anchored onto the membrane to improve the mass transfer (Noireaux and Libchaber, 2004). Recently, artificial cells based on porous hydrogels were constructed to conduct long-lived protein synthesis (Zhou et al., 2018; Lai et al., 2019). Although the interaction with the environment was a primary characteristic of a living system, the continuous supply of energy substrates might be limited in practice by the high costs and the specific feeding system.

\subsubsection{Self-Regeneration System}

It is worthwhile to construct a self-regeneration system for energy in an artificial cell from the perspective of reconstructing life. In nature, living cells can produce ATPs efficiently through the oxidation-phosphorylation and photo-phosphorylation processes, which can be summarized in two steps (Jeong et al., 2020). First, a proton gradient is established across the membrane boundary. In the oxidation-phosphorylation process, the driving force can be attributed to the oxidation of energy-rich molecules, in which electrons are transported through the electron transport chains (ETCs) (Nath and Villadsen, 2015). While in the photophosphorylation, it is driven by light with the help of photosynthetic pigments. Second, the proton gradient drives the ATP synthase (Nesci et al., 2015) to produce ATPs. The recovery of these two processes inside an artificial cell might lead to a self-sufficient supply of energy.

The construction of the ATP synthesis system can date back to 1974, when the purple membrane from Halobacferium halobium was packaged into phospholipid vesicles to support light-driven ATP synthesis (Racker and Stoeckenius, 1974). After that, the reconstitution of purified bacteriorhodopsin (bR) and ATP synthase in proteoliposomes enabled the formation of the proton gradient and ATP synthase (Sone et al., 1977). This indicated the possibility of ATP synthesis from completely synthetic components. In the next 30 years, the efficiency and stability of the ATP synthesis system were improved through the reconstitution of ATP synthases from bacteria (Richard et al., 1995; Choi et al., 2006), plants (Feng et al., 2016; Li et al., 2019) or mitochondria (Matuschka et al., 1995), and different types of proton gradient generators (Li et al., 2019; Tarryn et al., 2020; Xu 
et al., 2021). However, the membrane materials were generally based on lipids, probably due to their excellent compatibility with membrane proteins. Therefore, the various lipid compositions were studied to test their effects, and the protein densities were found to play a great role in ATP synthesis (Nilsson et al., 2016). In this case, the ATP synthesis system, or namely the artificial organelle for energy generation, was established in an efficient way.

These pre-prepared modules could be integrated into vesicles to drive other bioreactions. In 2018, a switchable ATP synthesis system, which could respond to light with different wavelengths, was coupled with actin polymerization and finally led to membrane growth (Lee et al., 2018). Then, in the next year, a similar photosynthetic organelle composed of bR proteins and ATP synthases was introduced into the recombinant cell-free system to support the complex transcription and translation processes (Berhanu et al., 2019). This fascinating result proved the compatibility of self-sufficient ATP synthesis with protein production. Recently, a chloroplast mimic with natural and synthetic parts was constructed to conduct a complete metabolic cycle for continuous $\mathrm{CO}_{2}$ fixing (Tarryn et al., 2020). Although significant progress has been achieved, these synthetic energy modules might still suffer from low efficiency. Most of them were only utilized in simple reaction cascades. A possible solution might be the loading of more functional proteins. For instance, the vast surfaces of mitochondria and chloroplasts in nature have enabled the complex metabolic networks inside cells. Therefore, the construction of membrane structures with a considerable surface area could facilitate the energy supplement in logic and finally help construct an energetically independent artificial cell.

\subsection{Proliferation}

Proliferation is a typical feature of a living cell, which generally refers to the generation of two daughter cells from one mother cell. This facilitates the population expansion of unicellular organisms and the development of advanced species. Moreover, the correct and steady proliferation has provided foundations for the Darwinian evolution, as the offspring should inherit most of the characteristics and a few mutations from parent generations. The detailed processes of proliferation have not been completely revealed. In this case, the construction of reproducible artificial cells could help us understand the possible mechanisms, and may play a role in synthetic tissues and organs, or other applicable fields. For an accurate description, here we mainly discuss the growth and division of one single artificial cell (Figure 2, Proliferation).

\subsubsection{Growth}

Growth represents the volume increase and mainly happens prior to the division. The metabolism should also get enhanced in this process. Generally, artificial cells could grow in three forms: absorbing materials from the environment, fusing with each other, and creating the materials from inside.

Membrane vesicles composed of fatty acids could absorb alkaline micelles spontaneously from outside and were first studied to imitate the cell growing process (Chen and Szostak,
2004; Stano and Luisi, 2010). This model might illustrate the state of primitive cells, but was probably not suitable for artificial cells with complex functions, as fatty acids were not compatible with some biological reactions and limited as a membrane material (Schwille et al., 2018). Afterward, phospholipid-based vesicles were successfully constructed to grow by fusing with each other. Giant unilamellar vesicles (GUVs) could gradually grow when supplied with small unilamellar vesicles (SUVs). The processes were mediated by the membrane tension through a transmembrane osmotic pressure (Deshpande et al., 2019b). To avoid the disordered fusion, the lipid membranes could be modified by specific molecules so that the fusion process could be initiated in the desired manner. For example, by using negatively charged lipids, the fusion of vesicles could be achieved through electrostatic repulsion (Terasawa et al., 2012). The growing process could also be light-controlled through the use of photo-sensitive surfactants (Suzuki et al., 2017). Besides, the protein-lipid interaction was proved promising for the induction of membrane tethering and fusion (Cai et al., 2019). Some polymer-based vesicles could grow upon integrating stimuli-responsive nanoparticles, which contained the membrane materials (Schwille et al., 2018). Compared with the absorption mechanism, the fusion process could supply other necessary substrates to meet the metabolic burden brought by the volume increase, thus might be popular in future studies. These two strategies both rely on the acquisition of the homologous membrane materials from the environment and reflect a primary growing form. A more lucrative way is that artificial cells synthesize their own membrane components and integrate them on the preexisting membrane. The synthesis of phospholipids has been achieved by purified enzymes in vitro (Schmidli et al., 1991), which provided a solid precondition. Recently, membrane growing was realized through the internal biosynthesis of lipids (Exterkate et al., 2018; Blanken et al., 2020). These excellent works would greatly improve the construction of an autonomous and selfreproducible artificial cell. Except for the volume increase, the morphological change was another growing form, such as the axon outgrowth. Artificial cells growing into asymmetric forms might help us to understand cell differentiation and deserve more exploring.

\subsubsection{Division}

As the next step of growth, division is almost inevitable for most cells. In this process, the cell membrane would deform to decrease its volume-to-surface ratio and become the dumbbell shape connected by a narrow membrane neck. Meanwhile, the interior is distributed into two different compartments. After the collapse of the membrane neck, the interior is separated, and the cell eventually divides into two daughter cells. Inspired by this, the division of an artificial cell could be resolved into the division of compartments and the allocation of crucial components such as genetic materials and enzymes. In the following text, these two aspects will be discussed in details.

GUVs are broadly used to study the division process, as they possess great fluidity and are most similar to natural membrane systems. By constructing fissionable GUVs, several models of 
membrane division induced by physical mechanism, chemical synthesis, or fundamental biological processes had been established (Caspi and Dekker, 2014). For example, some division machinery based on structure proteins, such as actomyosin and FtsZ, were found necessary in the division cycle. After the reconstitution of these proteins on GUVs, the liposome division could be observed in some cases (Osawa and Erickson, 2013). Besides, the cell-free synthesized bacterial division proto-rings could help to constrict liposomes and generate budding vesicles (Godino et al., 2020). This model relied on the specific splitting proteins anchored on lipid membranes. However, membrane fission could also be induced regardless of the protein structure. The steric pressure among the closely arranged membrane proteins could increase the membrane curvature and finally lead to a division. As a result, even green fluorescent proteins bounded on the membrane could drive fission efficiently (Snead et al., 2017). Furthermore, even low-density membrane proteins were feasible to induce the vesicle division by the precise control of the spontaneous membrane curvature (Steinkuhler et al., 2020). These efforts greatly decrease the complexity of the division process in vitro. However, they often resulted in unpredictable division results both of the volume and the components. As a result, microfluidics was applied to cut liposomes mechanically, thus precisely controlling the generation of daughter cells (Deshpande et al., 2018). This strategy could produce homogeneous offspring but be limited by the size of the vesicles and the specific wedge-shaped splitter. Recently, the spatiotemporal control of division was realized through the suitable osmolarity change based on the phase-separated GUVs. In this case, only the target GUVs would divide, while the others were not affected (Dreher et al., 2021). Based on these current works, one typical issue is that the allocation of the volume and components seems pretty random during the membrane fission. Considering the complex metabolism encapsulated inside vesicles, the precise and average division of the artificial mother cell would be pretty difficult. Some breakthroughs were achieved by the coupling of compartments and gene materials. Through the interaction between the negatively charged DNA and the cationic membrane, the division of the compartments could be linked with the amplification of DNA (Kurihara et al., 2011). As a result, the latter could significantly induce the growth and division of vesicles. On the other hand, RNA as another gene information carrier was encapsulated inside fatty acid vesicles and successfully distributed to the daughter cells (Zhu and Szostak, 2009). Nevertheless, these models could not illustrate the precisely average distribution of maternal genetic information. This is a crucial question, as the volume and other components might be separated mechanically through microfluidics, but the information materials should be replicated and distributed accurately.

Although the growth and division of artificial cells have distinctive processes, they all experience the change in volume or morphology. Especially, the asymmetric division, in which the offspring can inherit different components, should not be neglected, as it is inevitable in cell differentiation and various life course (Andes-Koback and Keating, 2011). In reference to the natural processes, the accurate distribution of gene materials and the precise control of division, both average and asymmetric, would be the focus of future works.

\subsection{Communication}

The three function modules discussed above were mainly based on one single artificial cell. However, information exchange is also a fundamental characteristic of a living cell, which means that it should react to various stimuli from the environment and cooperate or confront each other. Communications also broadly happen inside the compartments among interrelated function modules, as feedback is necessary to regulate complicated reaction networks. Here we would mainly talk about the communication between artificial cells and the environment, or among artificial cells (Figure 2, Communication).

\subsubsection{Basic Models}

Generally, the communication process requires three elements, the sender, the receiver, and the signal-transmitting information. The senders catch the signals released by the receivers and make responses accordingly. The signals could be physically, chemically, or biologically originated. The response could be the production or release of target molecules, cell motility, or just the simple changes in morphology. The simplest model of the artificial communication process is that an artificial cell receives signals from the environment and takes specific responses. For example, semipermeable compartments could allow the exchange of reaction substrates, thus facilitating protein synthesis (Zhou et al., 2018; Lai et al., 2019). The intelligent release of agents was realized based on the induction of various environmental stimuli, including $\mathrm{pH}$, osmotic pressure, light, ultrasound, and temperature (Fomina et al., 2010; Wang Y. C. et al., 2014; Basuki et al., 2017). However, the signal sources are not rigidly limited, which can also be artificially supplied. A more complex communication model requires specific signal senders. In this case, scientists aimed to construct another group of artificial sender cells, which released signals to the environment (Adamala et al., 2017; Joesaar et al., 2019). Except for all syntheses, natural cells could also be used as senders or receivers to interfere with artificial cells (Elani, 2021). Furthermore, based on the sender-receiver model, feedbacks could be introduced rather than one-way communication. For example, while the senders were the receivers themselves, they could regulate bioreactions based on their own products, which showed interesting collective behaviors as a community (Gines et al., 2017). Besides, the bidirectional communication was realized between artificial cells based on DNA strand-displacement circuits (Joesaar et al., 2019). Nevertheless, the typical communication types are not so rich. The construction of multi-directional communication still needs further studies, as well as the precise control of information processing.

\subsubsection{Simple Principles}

Signals hold an essential place in an artificial communication system, for they relate to the design of artificial cells and 
determine the transmission type. As discussed in Section 2.4.1, signals could be various. The intuitive method of receiving external signals utilizes stimuli-sensitive materials to construct receivers (Wang Y.-C. et al., 2014). These materials could change their morphology, swell or shrink, or modify their pore structures to regulate the transmission of signal molecules (Yavuz et al., 2009; Yan et al., 2013; Wang et al., 2020). More generally, it is applicable to introduce controlling modules from gene level, such as light-activated T7 promoter (Booth et al., 2016), various biosensors for small molecules, or specific ions (Jung et al., 2020; Thavarajah et al., 2020), to regulate the gene expression. This strategy is not limited by the sensitive materials. After the integration of different sensing modules inside one compartment, more complicated communication abilities would be practicable in artificial cells.

Another remarkable point is the transmission style of signals if information molecules are applied. Artificial cells could release or receive signals just through the diffusion of chemical molecules. Compared with the macromolecules, smaller molecules like $\mathrm{CO}_{2}$ (Yan et al., 2013), glucose (Arya et al., 2016), N-(3-oxohexanoyl)-L-homoserine lactone (3OC6HSL) (Lentini et al., 2017), can pass through the semipermeable membranes more easily, thus are broadly used as signals. Large molecules are also applicable, but they generally need large pore sizes or just membrane-free compartments. For example, DNA segments could diffuse into proteinosomes with porous structures to initiate the protein synthesis (Joesaar et al., 2019). Artificial cells based on clay hydrogels possessed large pores and even communicated through diffusive protein signals (Niederholtmeyer et al., 2018). These porous materials were more tolerant for molecular transfer than the traditional liposomes. Nonetheless, it would be more difficult to modify their surface with functional biological macromolecules compared with liposomes (Rideau et al., 2018). The impermeable molecules could go through the lipid membrane by the reconstitution of membrane pores, such as a-hemolysin (Adamala et al., 2017; Hilburger et al., 2019). These transmission processes were mostly driven by passive molecular motion and almost uncontrollable. They might be inefficient and interfere with each other in a complicated system with multi signals. To solve this problem, communications based on specific interactions have provided a feasible idea. For instance, the antibody binding could selectively target the specific bacterial and trigger a response when supplied in two groups of bacterial (Fernandes et al., 2010). Similar interaction includes the avidinbiotin complexation, which was realized in a synthetic vesicle-tovesicle communication system (Ding et al., 2019). These specific interactions mostly rely on the biomolecules anchoring on the membrane, and thus the bio-compatibility and modifiability of membrane materials are extremely important.

\subsubsection{Various Collective Behaviors}

Communication is a kind of group behavior, which involves a large number of individual artificial cells. Based on the sendersignal-receiver models mentioned above, various forms of communications could be established, whether they exist in reality or not. Quorum sensing (QS) is pretty common in bacterial populations, which refers to the regulation of gene expression in response to the concentration of autoinducers produced by bacteria themselves (Miller and Bassler, 2001). Quorum sensing is usually determined by the cell-population density. For instance, fluorescence could accumulate in artificial cells only at high densities by using T3 RNA polymerases as QS signals (Niederholtmeyer et al., 2018). The signal molecules could also spread and form spatial distribution to induce different activities like pulses and waves in the artificial cell groups (Tayar et al., 2015). In contrast to this heterogeneous phenomena, synchrony and pattern formation were also realized through the nonlinear genetic oscillators coupling on a chip of artificial cells (Tayar et al., 2017). However, this collective behavior was still hard to be reproduced in vitro, probably due to the low robustness of cell-free oscillators. Another exciting application of the synthetic communication process is to mimic the natural differentiation of cell groups, which is the basis of development for advanced species. For example, by implementing different types of feedback gene circuits, artificial cells could exhibit differentiated gene expression during the signaling process (Dupin and Simmel, 2019). In a word, the studies of synthetic communication systems would not only improve our cognitions of collective cellular behaviors but facilitate the construction of a dynamically connected artificial cell community.

\subsubsection{Evolution}

Evolution is a typical and crucial characteristic of life (Szostak et al., 2001; Schwille et al., 2018). Here we put it in this section as it reflects the communication between artificial cells and the environment. The artificial cells can react to the environmental pressure and take a response to change themselves, which could be inherited by their future generations. Therefore, the evolution process is largely related to the information coupled with the fitness of artificial cells. A typical model was that RNAs with special structures coupled with the interior vesicle wall could facilitate the stability of vesicle and improve survival (Szostak et al., 2001). The complementary pairing between short oligonucleotides and replicase ribozymes was also studied as an evolution system model (Engelhart et al., 2016). The oligonucleotides could combine with the ribozymes and inhibit vesicle growth. In addition to the typical responsereceive model, the tight connection between the response and the survival of artificial cells is also required to provide the evolution engine. Since the proliferation of artificial cells has not been stably achieved, the construction of artificial evolution systems still has a long way to go. However, it should be considered necessary to build a self-sustaining artificial cell.

\section{UNITY}

The increased library size and quality of building blocks would broaden the diversity and functionality of artificial cells. The next question is how to assemble these modules into a complete artificial cell (Figure 3). This idea could be naturally generated. For example, when constructing a light-powered or 

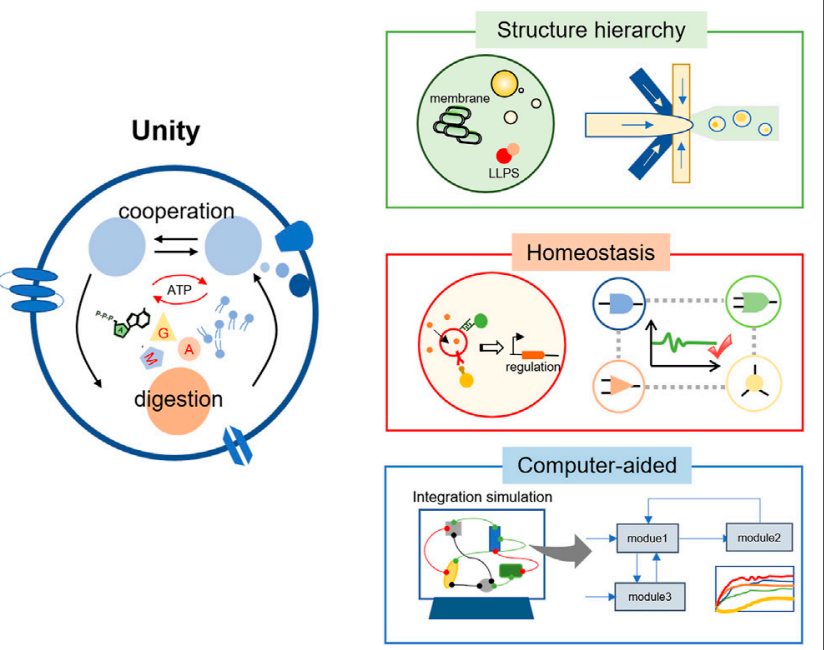

FIGURE 3 | The integration of different modules into a functional artificial cell. Reestablishing the structure hierarchy of living cells is practical, which refers to the multicompartment and the complex membrane system inside an artificial cell. In addition, the regulation system of different modules should be constructed to maintain the homeostasis. Considering the extremely complicated interactions, the computer-aided technology would have wide applications in the integration of basic models and even the design of a complete artificial cell.

communicative artificial cell, the intuitive evaluating method is to couple the target process with the synthesis of fluorescent proteins. However, with the increasing amounts of building blocks, they might be interpreted by each other and counteract to decrease the efficiency as a whole. A typical example could be the competition between different modules for the common substrates.

Millions of years of evolution have endowed living cells with a complex structure to overcome this difficulty. A natural eukaryotic cell has various organelles with different compositions and assumes different cellular functions (Zhu et al., 2020). Even prokaryotic cells have nucleoids and ribosomes. This hierarchy helps to separate different modules to ensure they function in a proper condition. The coordination of various organelles has made cells a highly-ordered biochemical machine. This phenomenon inspired us that the multicompartment structure could help to integrate the building blocks toward a complicated artificial cell. Through encapsulating functional modules into different subcompartments, one can achieve the spatiotemporal organization inside an artificial cell. Simple two-dimensional nesting structures could be formed through careful regulation during the fabricating of large vesicles (Dora Tang et al., 2014; Booth et al., 2019). However, this method could be primarily influenced by the operators when dealing with more complex architecture. On the other hand, the nested droplets produced by microfluidics have been studied as mimics of eukaryotic cells ( $\mathrm{Ai}$ et al., 2020). For instance, separated transcription and translation processes were realized inside multicompartment droplets (Aufinger and Simmel, 2018). Artificial nuclei were encapsulated inside hydrogels through the water-in-oil-in- water double emulsion (Niederholtmeyer et al., 2018). The microfluidics could also provide an easily-operated platform for the induction of membrane-less compartments inside artificial cells (Deshpande et al., 2019a; Love et al., 2020). The technology can generate standard and monodisperse droplets as artificial cells, thus are widely-used and promising in this field, but they might suffer from poorly stable structures (Martino and deMello, 2016; Deshpande and Dekker, 2019).

Many enzymatic reactions mainly happen in cell-free solutions in artificial cells. However, the bio-membrane system is an important characteristic of life, which greatly increases the surface-to-volume proportion, supports functional proteins, and improves the efficiency of bioreactions. Inspired by this, the reconstitution of membrane proteins on synthetic membranes, such as lipids and amphiphilic block copolymers, has been broadly studied. These membrane proteins could form biopores to improve the mass transfer (Garni et al., 2017; Shen et al., 2018), induce the membrane deformation (Steinkuhler et al., 2020), or play a catalytic role (Choi et al., 2006). As artificial cells could provide a great platform for studying membrane proteins in vitro, more functional artificial membranes might be developed in the future. Compared with the complete synthesis, another appealing method is to utilize the natural membrane system. For example, thylakoid membranes were directly used to construct the artificial chloroplast and make outstanding achievements in optical conversion efficiency (Tarryn et al., 2020). These efforts have simplified the construction process while retaining the complexity of the artificial system (Figure 3, Structure hierarchy).

After the multicompartment of different functional modules, the question could be naturally put forward that whether these separated modules could function efficiently. Fortunately, the bioreactions such as protein synthesis had a better performance in a confined environment than in bulk solution (Park et al., 2009), probably due to the high local concentration of enzymes and substrates. However, it was not the case in an artificial cell with a higher structure hierarchy, for complex metabolism behaviors usually became difficult to reconstitute (Berhanu et al., 2019). This was partly attributed to low efficiency of the bioreactions in vitro, and continuous efforts to optimize the cellfree system would still make sense. In addition, the allocation of resources inside artificial cells was probably far away from the optimum. For example, in a passive diffusion case, the output of one module would diffuse outside and come into another module randomly. As a result, the signals might distribute evenly in the artificial cell, trigger the bioprocess in an inefficient way, and waste the limited resources in the confined space. To solve this problem, a distinctive and specific pathway is promoted for signal receiving and processing. For example, the complementary base pairing was applied in the intracellular communication of artificial organelles to trigger specific communication (Aufinger and Simmel, 2018). Afterward, the feedback system should be established, which means the different modules could regulate the production of signals based on the concentration to reach homeostasis. Through careful regulation, we might keep them at the optimum concentration to get the efficient allocation of materials and energy (Figure 3, Homeostasis). However, this 
would be pretty difficult as the precise operation of bioreactions inside a tiny compartment was still not so mature, and thus new technology is expected in this field.

The unity of different functional modules toward a complete artificial cell is a significant and laborious task, as the involved interactions are highly complicated. In this case, computer-aided technology would provide a more feasible and time-saving approach (Figure 3, Computer-aided). Computational and mathematical modeling has been widely used to investigate or predict the potential dynamics in artificial cells (Cho and $\mathrm{Lu}$, 2020). These include the biochemistry effects in a confined environment (Sakamoto et al., 2018), the communication behaviors triggered by signal molecules (Rampioni et al., 2014), or the design of membrane proteins on lipids (Alford et al., 2020). Recently, the module assembling process was successfully established through the computer-aided design, which consisted of a membrane proliferating module, a membrane contraction module, and a positioning module (Schneider and Mangold, 2018). This result has greatly revealed the advance of computer-aided technology. It would help us to understand the complicated mechanism of synthetic bio-processes and bring new opportunities to the art of constructing artificial cells.

\section{CHALLENGES AND PROSPECTS}

The construction of artificial cells is not a task that can be accomplished in the short term. It is an interdisciplinary field, which covers almost all of the scientific or engineering subjects. We proposed constructing artificial cells from functional modules to simplify the inherent complexity of this task. In this case, this complicated project could be separated into several smaller tasks, with the full use of strength worldwide. A bio-engineering workflow has been put forward to promote the standardization for the construction of artificial cells (Schwille et al., 2018). In the systematic design of a biosystem, four elements should be considered, including the precise definition of the biosystem's functionalities, the experimental validation of the functional modules, the reliable assembling of different modules, and the production of the biosystem in a reproducible manner. If we consider an artificial cell a precise machine, we are still struggling to invent new accessories, assemble them and broaden the final functionalities.

\subsection{Challenges}

The functions of an artificial cell could be divided into four essential parts: metabolism, energy supplement, proliferation, and communication. Among these four parts, metabolism is the most fundamental, as the other three could be formally attributed to bioreactions. Up to now, only simple bioreactions have been realized when encapsulated inside artificial cells. The low efficiency and simplified reaction processes have greatly hindered the application of the synthetic compartments. In energy analysis, this could be partly attributed to the short supplement of energy. Therefore, more efficient energy supplements and their well-coupling with the core metabolic process are in urgent need. In the proliferation part, how to connect the replication of internal chemicals with the precise and reproducible division of compartments is the main challenge. As for the communication module, it is wondered how the communication among artificial cell populations could affect the development or differentiation of individuals. In other words, the interactions at a collective level are also crucial in describing an artificial cell. Furthermore, the integration of these different modules also requires more deep researches. The challenge would be the achievement of an elaborate organization rather than a simple stack. The latter might cause competition for resources and internal friction.

\subsection{Possible Solutions}

The challenges in the four modules and their efficient integration should be considered carefully, and several possible solutions are proposed here for further discussion. To improve metabolism efficiency and diversity, the cell-free system should be developed to support the robust synthesis of different proteins. The connotation of the system needs to be expanded. For example, the riboswitches, chaperons, or some post-translation modification factors could be introduced for regulation. The system could also perform not only as a synthesis machine but also as a rubbish factory to enable substrate circulation. At the same time, since the energy supply in a living cell is significant, the combination of natural energy parts and synthetic systems would be efficient as a transition toward a reconstituted energy supply system. The external supplement and self-regeneration could also coordinate in one single artificial cell to work more remarkably. As for the precise control of proliferation, the mechanical division through microfluidic technology might be a possible strategy. A self-driving division model might rely on the interaction between the replication of the interior and the membrane motility. For example, if the genetic materials were linked with the membrane, their replication might induce the change of the membrane morphology. Since there might be an optimized quantitative relationship between genes and membranes, precise and average division might be achieved. In the communication part, different types of releasing and receiving processes for signals might be developed except for different signals through one transmission mode. For example, the hybridization between antigens and antibodies could happen on the surface of artificial cells, while small molecules diffuse into the interior to function. In this case, a complex communication system could be established for further observation of collective behaviors. At last, for efficient integration of different modules, the multicompartment and membrane systems could be the structure basis, while the optimized allocation of resources and the feedback system toward homeostasis would finally support the well-organized bio-machine.

The modulization and unity strategy could be appropriate for the complicated subject of constructing artificial cells. The following work would concentrate on expanding the module library and the efficient assembling of these modules based on the desired function. Artificial cells are firstly mimics of living cells. Therefore, the bottomup construction could probably gain inspiration from the natural world. However, these man-made bio-machines could be more than 
cells, which means that they could exhibit unprecedented phenotypes or have unordinary functions. With the development of relative fields, artificial cells could improve our cognition toward life and help to improve the quality of our real-life for their application in diagnostics and therapeutics.

\section{AUTHOR CONTRIBUTIONS}

CW, JY, and YL contributed to conception and design of the study. CW wrote the first draft of the manuscript. All authors

\section{REFERENCES}

Adamala, K. P., Martin-Alarcon, D. A., Guthrie-Honea, K. R., and Boyden, E. S. (2017). Engineering Genetic Circuit Interactions within and between Synthetic Minimal Cells. Nat. Chem. 9, 431-439. doi:10.1038/nchem.2644

Ai, Y., Xie, R., Xiong, J., and Liang, Q. (2020). Microfluidics for Biosynthesizing: From Droplets and Vesicles to Artificial Cells. Small 16, e1903940. doi:10.1002/ smll.201903940

Alford, R. F., Fleming, P. J., Fleming, K. G., and Gray, J. J. (2020). Protein Structure Prediction and Design in a Biologically Realistic Implicit Membrane. Biophysical J. 118, 2042-2055. doi:10.1016/j.bpj.2020.03.006

Almén, M. S., Nordström, K. J. V., Fredriksson, R., and Schiöth, H. B. (2009). Mapping the Human Membrane Proteome: A Majority of the Human Membrane Proteins Can Be Classified According to Function and Evolutionary Origin. BMC Biol. 7, 50. doi:10.1186/1741-7007-7-50

Andes-Koback, M., and Keating, C. D. (2011). Complete Budding and Asymmetric Division of Primitive Model Cells to Produce Daughter Vesicles with Different interior and Membrane Compositions. J. Am. Chem. Soc. 133, 9545-9555. doi:10.1021/ja202406v

Arya, C., Oh, H., and Raghavan, S. R. (2016). "Killer" Microcapsules that Can Selectively Destroy Target Microparticles in Their Vicinity. ACS Appl. Mater. Inter. 8, 29688-29695. doi:10.1021/acsami.6b10097

Ashley, C. E., Carnes, E. C., Phillips, G. K., Padilla, D., Durfee, P. N., Brown, P. A., et al. (2011). Erratum: The Targeted Delivery of Multicomponent Cargos to Cancer Cells by Nanoporous Particle-Supported Lipid Bilayers. Nat. Mater 10, 476. doi:10.1038/nmat3042

Aufinger, L., and Simmel, F. C. (2018). Artificial Gel-Based Organelles for Spatial Organization of Cell-free Gene Expression Reactions. Angew. Chem. Int. Ed. Engl. 57, 17245-17248. doi:10.1002/anie.201809374

Bai, J., Liu, M., Pielak, G. J., and Li, C. (2017). Macromolecular and Small Molecular Crowding Have Similar Effects on a-synuclein Structure. ChemPhysChem 18, 55-58. doi:10.1002/cphc.201601097

Basuki, J. S., Qie, F., Mulet, X., Suryadinata, R., Vashi, A. V., Peng, Y. Y., et al. (2017). Photo-modulated Therapeutic Protein Release from a Hydrogel Depot Using Visible Light. Angew. Chem-int Edit. 56, 966-971. doi:10.1002/anie.201610618

Berhanu, S., Ueda, T., and Kuruma, Y. (2019). Artificial Photosynthetic Cell Producing Energy for Protein Synthesis. Nat. Commun. 10, 1325. doi:10.1038/s41467-019-09147-4

Blanken, D., Foschepoth, D., Serrão, A. C., and Danelon, C. (2020). Genetically Controlled Membrane Synthesis in Liposomes. Nat. Commun. 11, 4317. doi:10.1038/s41467-020-17863-5

Bonam, S. R., Wang, F., and Muller, S. (2019). Lysosomes as a Therapeutic Target. Nat. Rev. Drug Discov. 18, 923-948. doi:10.1038/s41573-019-0036-1

Booth, M. J., Schild, V. R., Graham, A. D., Olof, S. M., and Bayley, H. (2016). Lightactivated Communication in Synthetic Tissues. Sci. Adv. 2, e1600056. doi:10.1126/sciadv.1600056

Booth, R., Qiao, Y., Li, M., and Mann, S. (2019). Spatial Positioning and Chemical Coupling in Coacervate-In-Proteinosome Protocells. 58, 9120-9124. doi: doi:10.1002/anie.201903756

Cai, B., Yu, L., Sharum, S. R., Zhang, K., and Diao, J. (2019). Single-vesicle Measurement of Protein-Induced Membrane Tethering. Colloids Surf. B Biointerfaces 177, 267-273. doi:10.1016/j.colsurfb.2019.02.004 contributed to manuscript revision, read, and approved the submitted version.

\section{FUNDING}

This work was supported by Beijing Natural Science Foundation (2192023), National Natural Science Foundation of China (21878173), National Key R\&D Program of China (2018YFA0901700), and the Institute for Guo Qiang, Tsinghua University (2019GQG1016).

Carreira, A. C., de Almeida, R. F. M., and Silva, L. C. (2017). Development of Lysosome-Mimicking Vesicles to Study the Effect of Abnormal Accumulation of Sphingosine on Membrane Properties. Sci. Rep. 7, 3949. doi:10.1038/s41598017-04125-6

Caschera, F., and Noireaux, V. (2014). Synthesis of $2.3 \mathrm{Mg} / \mathrm{ml}$ of Protein with an All escherichia Coli Cell-free Transcription-Translation System. Biochimie 99, 162-168. doi:10.1016/j.biochi.2013.11.025

Caspi, Y., and Dekker, C. (2014). Divided We Stand: Splitting Synthetic Cells for Their Proliferation. Syst. Synth. Biol. 8, 249-269. doi:10.1007/s11693-0149145-7

Chang, T. M. S. (2005). Therapeutic Applications of Polymeric Artificial Cells. Nat. Rev. Drug Discov. 4, 221-235. doi:10.1038/nrd1659

Chen, I. A., and Szostak, J. W. (2004). A Kinetic Study of the Growth of Fatty Acid Vesicles. Biophys. J. 87, 988-998. doi:10.1529/biophysj.104.039875

Cho, E., and Lu, Y. (2020). Compartmentalizing Cell-free Systems: Toward Creating Life-like Artificial Cells and beyond. ACS Synth. Biol. 9, 2881-2901. doi:10.1021/acssynbio.0c00433

Choi, H.-J., Germain, J., and Montemagno, C. D. (2006). Effects of Different Reconstitution Procedures on Membrane Protein Activities in Proteopolymersomes. Nanotechnology 17, 1825-1830. doi:10.1088/09574484/17/8/003

Deng, N.-N., Vibhute, M. A., Zheng, L., Zhao, H., Yelleswarapu, M., and Huck, W. T. S. (2018). Macromolecularly Crowded Protocells from Reversibly Shrinking Monodisperse Liposomes. J. Am. Chem. Soc. 140, 7399-7402. doi:10.1021/ jacs.8b03123

Des Soye, B. J., Davidson, S. R., Weinstock, M. T., Gibson, D. G., and Jewett, M. C. (2018). Establishing a High-Yielding Cell-free Protein Synthesis Platform Derived from vibrio Natriegens. ACS Synth. Biol. 7, 2245-2255. doi:10.1021/ acssynbio.8b00252

Deshpande, S., Brandenburg, F., Lau, A., Last, M. G. F., Kasper Spoelstra, W., Reese, L., et al. (2019a). Spatiotemporal Control of Coacervate Formation within Liposomes. Nat. Commun. 10, 1800. doi:10.1038/s41467-01909855-x

Deshpande, S., and Dekker, C. (2021). Studying Phase Separation in Confinement. Curr. Opin. Colloid Interf. Sci. 52, 101419. doi:10.1016/j.cocis.2021.101419

Deshpande, S., and Dekker, C. (2019). Synthetic Life on a Chip. Emerging Top. Life Sci. 3, 559-566. doi:10.1042/ETLS20190097

Deshpande, S., Spoelstra, W. K., van Doorn, M., Kerssemakers, J., Dekker, C., et al. (2018). Mechanical Division of Cell-Sized Liposomes. ACS Nano 12, 2560-2568. doi:10.1021/acsnano.7b08411

Deshpande, S., Wunnava, S., Hueting, D., and Dekker, C. (2019b). Membrane Tension-Mediated Growth of Liposomes. Small 15, e1902898. doi:10.1002/ smll.201902898

Ding, Y., Williams, N. H., and Hunter, C. A. (2019). A Synthetic Vesicle-To-Vesicle Communication System. J. Am. Chem. Soc. 141, 17847-17853. doi:10.1021/ jacs.9b09102

Dora Tang, T.-Y., Rohaida Che Hak, C., Thompson, A. J., Kuimova, M. K., Williams, D. S., Perriman, A. W., et al. (2014). Fatty Acid Membrane Assembly on Coacervate Microdroplets as a Step towards a Hybrid Protocell Model. Nat. Chem. 6, 527-533. doi: doi:10.1038/nchem.1921

Dreher, Y., Jahnke, K., Bobkova, E., Spatz, J. P., and Göpfrich, K. (2021). Division and Regrowth of Phase-Separated Giant Unilamellar Vesicles. Angew. Chem. Int. Ed. Engl. 60, 10661-10669. doi:10.1002/anie.202014174 
Dupin, A., and Simmel, F. C. (2019). Signalling and Differentiation in EmulsionBased Multi-Compartmentalized In Vitro Gene Circuits. Nat. Chem. 11, 32-39. doi:10.1038/s41557-018-0174-9

Elani, Y. (2021). Interfacing Living and Synthetic Cells as an Emerging Frontier in Synthetic Biology. Angew. Chem. Int. Ed. Engl. 60, 5602-5611. doi:10.1002/ anie. 202006941

Ellis, R. J. (2001). Macromolecular Crowding: An Important but Neglected Aspect of the Intracellular Environment. Curr. Opin. Struct. Biol. 11, 114-119. doi:10.1016/s0959-440x(00)00172-x

Engelhart, A. E., Adamala, K. P., and Szostak, J. W. (2016). A Simple Physical Mechanism Enables Homeostasis in Primitive Cells. Nat. Chem. 8, 448-453. doi:10.1038/nchem. 2475

Exterkate, M., Caforio, A., Stuart, M. C. A., and Driessen, A. J. M. (2018). Growing Membranes In Vitro by Continuous Phospholipid Biosynthesis from Free Fatty Acids. ACS Synth. Biol. 7, 153-165. doi:10.1021/acssynbio.7b00265

Feng, X., Jia, Y., Cai, P., Fei, J., and Li, J. (2016). Coassembly of Photosystem Ii and Atpase as Artificial Chloroplast for Light-Driven Atp Synthesis. ACS Nano 10, 556-561. doi:10.1021/acsnano.5b05579

Fernandes, R., Roy, V., Wu, H. C., and Bentley, W. E. (2010). Engineered Biological Nanofactories Trigger Quorum Sensing Response in Targeted Bacteria. Nat. Nanotechnol 5, 213-217. doi:10.1038/nnano.2009.457

Fomina, N., McFearin, C., Sermsakdi, M., Edigin, O., and Almutairi, A. (2010). Uv and Near-Ir Triggered Release from Polymeric Nanoparticles. J. Am. Chem. Soc. 132, 9540-9542. doi:10.1021/ja102595j

Fujiwara, K., and Nomura, S. M. (2013). Condensation of an Additive-free Cell Extract to Mimic the Conditions of Live Cells. PLoS One 8, e54155. doi:10.1371/ journal.pone. 0054155

Furusato, T., Horie, F., Matsubayashi, H. T., Amikura, K., Kuruma, Y., and Ueda, T. (2018). De Novo synthesis of Basal Bacterial Cell Division Proteins Ftsz, Ftsa, and Zipa inside Giant Vesicles. ACS Synth. Biol. 7, 953-961. doi:10.1021/ acssynbio.7b00350

Garni, M., Thamboo, S., Schoenenberger, C. A., and Palivan, C. G. (2017). Biopores/membrane Proteins in Synthetic Polymer Membranes. Biochim. Biophys. Acta Biomembr 1859, 619-638. doi:10.1016/j.bbamem.2016.10.015

Ge, X., Luo, D., and Xu, J. (2011). Cell-free Protein Expression under Macromolecular Crowding Conditions. PLOS ONE 6, e28707. doi:10.1371/ journal.pone. 0028707

Gibson, D. G., Glass, J. I., Lartigue, C., Noskov, V. N., Chuang, R. Y., Algire, M. A., et al. (2010). Creation of a Bacterial Cell Controlled by a Chemically Synthesized Genome. Science 329, 52-56. doi:10.1126/science.1190719

Gines, G., Zadorin, A. S., Galas, J. C., Fujii, T., Estevez-Torres, A., and Rondelez, Y. (2017). Microscopic Agents Programmed by DNA Circuits. Nat. Nanotechnology 12, 351-359. doi:10.1038/nnano.2016.299

Godino, E., López, J. N., Foschepoth, D., Cleij, C., Doerr, A., Ferrer Castellà, C., et al. (2019). De Novo synthesized Min Proteins Drive Oscillatory Liposome Deformation and Regulate Ftsa-Ftsz Cytoskeletal Patterns. Nat. Commun. 10, 4969. doi:10.1038/s41467-019-12932-w

Godino, E., López, J. N., Zarguit, I., Doerr, A., Jimenez, M., Rivas, G., et al. (2020). Cell-free Biogenesis of Bacterial Division Proto-Rings that Can Constrict Liposomes. Commun. Biol. 3, 539. doi:10.1038/s42003-020-01258-9

Goerke, A. R., and Swartz, J. R. (2008). Development of Cell-free Protein Synthesis Platforms for Disulfide Bonded Proteins. Biotechnol. Bioeng. 99, 351-367. doi:10.1002/bit.21567

Hibi, K., Amikura, K., Sugiura, N., Masuda, K., Ohno, S., Yokogawa, T., et al. (2020). Reconstituted Cell-free Protein Synthesis Using In Vitro Transcribed Trnas. Commun. Biol. 3, 350. doi:10.1038/s42003-020-1074-2

Hilburger, C. E., Jacobs, M. L., Lewis, K. R., Peruzzi, J. A., Kamat, N. P., et al. (2019). Controlling Secretion in Artificial Cells with a Membrane and Gate. ACS Synth. Biol. 8, 1224-1230. doi:10.1021/acssynbio.8b00435

Huang, X., Li, M., Green, D. C., Williams, D. S., Patil, A. J., and Mann, S. (2013). Interfacial Assembly of Protein-Polymer Nano-Conjugates into Stimulus-Responsive Biomimetic Protocells. Nat. Commun. 4, 2239. doi:10.1038/ncomms3239

Jayaraman, P., Yeoh, J. W., Jayaraman, S., Teh, A. Y., Zhang, J., and Poh, C. L. (2018). Cell-free Optogenetic Gene Expression System. ACS Synth. Biol. 7, 986-994. doi:10.1021/acssynbio.7b00422

Jeong, S., Nguyen, H. T., Kim, C. H., Nguyet Ly, M., and Shin, K. (2020). Toward Artificial Cells: Novel Advances in Energy Conversion and Cellular Motility. Adv. Funct. Mater. 30. doi:10.1002/adfm.201907182
Jewett, M. C., and Swartz, J. R. (2004). Mimicking the escherichia Coli Cytoplasmic Environment Activates Long-Lived and Efficient Cell-free Protein Synthesis. Biotechnol. Bioeng. 86, 19-26. doi:10.1002/bit.20026

Jewett, M., Fritz, B., Timmerman, L., and Church, G. M. (2013). In Vitro integration of Ribosomal Rna Synthesis, Ribosome Assembly, and Translation. Mol. Syst. Biol. 9, 678. doi:10.1038/msb.2013.31

Joesaar, A., Yang, S., Bögels, B., van der Linden, A., Pieters, P., Kumar, B. V. V. S. P., et al. (2019). DNA-based Communication in Populations of Synthetic Protocells. Nat. Nanotechnol. 14, 369-378. doi:10.1038/s41565-019-0399-9

Jung, J. K., Alam, K. K., Verosloff, M. S., Capdevila, D. A., Desmau, M., Clauer, P. R., et al. (2020). Cell-free Biosensors for Rapid Detection of Water Contaminants. Nat. Biotechnol. 38, 1451-1459. doi:10.1038/s41587-0200571-7

Karzbrun, E., Tayar, A. M., Noireaux, V., and Bar-Ziv, R. H. (2014). Programmable On-Chip DNA Compartments as Artificial Cells. 345, 829-832. doi: doi:10.1126/science. 1255550

Kightlinger, W., Duncker, K. E., Ramesh, A., Thames, A. H., Natarajan, A., Stark, J. C., et al. (2019). A Cell-free Biosynthesis Platform for Modular Construction of Protein Glycosylation Pathways. Nat. Commun. 10, 5404. doi:10.1038/ s41467-019-12024-9

Kim, D.-M., and Choi, C.-Y. (1996). A Semicontinuous Prokaryotic Coupled Transcription/translation System Using a Dialysis Membrane. 12, 645-649. doi: doi:10.1021/bp960052l

Kim, H.-C., Kim, T.-W., and Kim, D.-M. (2011). Prolonged Production of Proteins in a Cell-free Protein Synthesis System Using Polymeric Carbohydrates as an Energy Source. Process Biochem. 46, 1366-1369. doi:10.1016/ j.procbio.2011.03.008

Kim, T. W., Oh, I. S., Keum, J. W., Kwon, Y-C., Byun, J-Y., Lee, K-H., et al. (2007). Prolonged Cell-free Protein Synthesis Using Dual Energy Sources: Combined Use of Creatine Phosphate and Glucose for the Efficient Supply of Atp and Retarded Accumulation of Phosphate. Biotechnol. Bioeng. 97, 1510-1515. doi:10.1002/bit.21337

Kurihara, K., Tamura, M., Shohda, K., Toyota, T., and Suzuki, K. (2011). Selfreproduction of Supramolecular Giant Vesicles Combined with the Amplification of Encapsulated DNA. Nat. Chem. 3, 775-781. doi:10.1038/ nchem. 1127

Lai, S. N., Zhou, X., Ouyang, X., Zhou, H., Liang, Y., Xia, J., et al. (2019). Artificial Cells Capable of Long-Lived Protein Synthesis by Using Aptamer Grafted Polymer Hydrogel. ACS Synth. Biol. 9, 76-83. doi:10.1021/ acssynbio. $9 \mathrm{~b} 00338$

Last, M. G. F., Deshpande, S., and Dekker, C. (2020). Ph-controlled Coacervate-Membrane Interactions within Liposomes. ACS Nano 14, 4487-4498. doi:10.1021/acsnano.9b10167

Lavickova, B., Laohakunakorn, N., and Maerkl, S. J. (2020). A Partially SelfRegenerating Synthetic Cell. Nat. Commun. 11, 6340. doi:10.1038/s41467-02020180-6

Lavickova, B., and Maerkl, S. J. (2019). A Simple, Robust, and Low-Cost Method to Produce the Pure Cell-free System. ACS Synth. Biol. 8, 455-462. doi:10.1021/ acssynbio.8b00427

Lee, K. Y., Park, S.-J., Lee, K. A., Kim, S.-H., Kim, H., Meroz, Y., et al. (2018). Photosynthetic Artificial Organelles Sustain and Control Atp-dependent Reactions in a Protocellular System. Nat. Biotechnol. 36, 530-535. doi: $10.1038 /$ nbt.4140

Lentini, R., Martín, N. Y., Forlin, M., Belmonte, L., Fontana, J., Cornella, M., et al. (2017). Two-way Chemical Communication between Artificial and Natural Cells. ACS Cent. Sci. 3, 117-123. doi:10.1021/acscentsci.6b00330

Li, Y., Feng, X., Wang, A., Yang, Y., Fei, J., Sun, B., et al. (2019). Supramolecularly Assembled Nanocomposites as Biomimetic Chloroplasts for Enhancement of Photophosphorylation. Angew. Chem. Int. Ed. Engl. 58, 796-800. doi:10.1002/ anie. 201812582

Libicher, K., Hornberger, R., Heymann, M., and Mutschler, H. (2020). In Vitro selfreplication and Multicistronic Expression of Large Synthetic Genomes. Nat. Commun. 11. doi:10.1038/s41467-020-14694-2

Liu, J., Stace-Naughton, A., Jiang, X., and Brinker, C. J. (2009). Porous Nanoparticle Supported Lipid Bilayers (Protocells) as Delivery Vehicles. J. Am. Chem. Soc. 131, 1354, 1355-+. doi: doi:10.1021/ja808018y

Love, C., Steinkühler, J., Gonzales, D. T., Yandrapalli, N., Robinson, T., Dimova, R., et al. (2020). Reversible Ph-Responsive Coacervate Formation in Lipid Vesicles 
Activates Dormant Enzymatic Reactions. Angew. Chem. Int. Ed. Engl. 59, 5950-5957. doi:10.1002/anie.201914893

Lu, Y. (2017). Cell-free Synthetic Biology: Engineering in an Open World. Arch. Sci. 2, 23-27. doi:10.1016/j.synbio.2017.02.003

Ma, Q., Song, Y., Sun, W., Cao, J., Yuan, H., Wang, X., et al. (2020). Cell-inspired All-Aqueous Microfluidics: From Intracellular Liquid-Liquid Phase Separation toward Advanced Biomaterials. Adv. Sci. (Weinh) 7, 1903359. doi:10.1002/ advs.201903359

Martino, C., and deMello, A. J. (2016). Droplet-based Microfluidics for Artificial Cell Generation: A brief Rev. 6, 20160011. doi: doi:doi:10.1098/rsfs.2016.0011

Matsuo, M., Kan, Y., Kurihara, K., Jimbo, T., Imai, M., Toyota, T., et al. (2019). DNA Length-dependent Division of a Giant Vesicle-Based Model Protocell. Sci. Rep. 9, 11. doi:10.1038/s41598-019-43367-4

Matuschka, S., Zwicker, K., and Nawroth, T. (1995). Atp Synthesis by Purified AtpSynthase from Beef Heart Mitochondria after Coreconstitution with Bacteriorhodopsin. Arch. Biochem. Biophys. 322, 135-142. doi:10.1006/ abbi. 1995.1445

Miller, M. B., and Bassler, B. L. (2001). Quorum sensing in Bacteria. Annu. Rev. Microbiol. 55, 165-199. doi:10.1146/annurev.micro.55.1.165

Minton, A. P. (2006). How Can Biochemical Reactions within Cells Differ from Those in Test Tubes? J. Cel Sci. 119, 2863-2869. doi:10.1242/jcs.03063

Minton, A. P. (2015). How Can Biochemical Reactions within Cells Differ from Those in Test Tubes? J. Cel Sci 128, 1254. doi:10.1242/jcs.170183

Nath, S., and Villadsen, J. (2015). Oxidative Phosphorylation Revisited. 112, 429-437. doi: doi:10.1002/bit.25492

Nesci, S., Trombetti, F., Ventrella, V., and Pagliarani, A. (2015). Opposite Rotation Directions in the Synthesis and Hydrolysis of Atp by the Atp Synthase: Hints from a Subunit Asymmetry. J. Membr. Biol. 248, 163-169. doi:10.1007/s00232014-9760-y

Niederholtmeyer, H., Chaggan, C., and Devaraj, N. K. (2018). Communication and Quorum Sensing in Non-living Mimics of Eukaryotic Cells. Nat. Commun. 9, 5027. doi:10.1038/s41467-018-07473-7

Niederholtmeyer, H., Stepanova, V., and Maerkl, S. J. (2013). Implementation of Cell-free Biological Networks at Steady State. Proc. Natl. Acad. Sci. U S A. 110, 15985-15990. doi:10.1073/pnas.1311166110

Nilsson, T., Lundin, C. R., Nordlund, G., Ädelroth, P., Ballmoos, C. V., and Brzezinski, P. (2016). Lipid-mediated Protein-Protein Interactions Modulate Respiration-Driven Atp Synthesis. Scientific Rep. 6, 24113. doi:10.1038/ srep24113

Nirenberg, M. W., and Matthaei, J. H. (1961). The dependence of cell-free protein synthesis in e. Coli upon naturally occurring or synthetic polyribonucleotides. \% J. Proc. Natl. Acad. Sci. 47, 1588-1602. doi:10.1073/pnas.47.10.1588

Noireaux, V., and Libchaber, A. (2004). A Vesicle Bioreactor as a Step toward an Artificial Cell Assembly. Proc. Natl. Acad. Sci. U S A. 101, 17669-17674. doi:10.1073/pnas.0408236101

Noireaux, V., Bar-Ziv, R., Godefroy, J., Salman, H., and Libchaber, A. (2005). Toward an Artificial Cell Based on Gene Expression in Vesicles. Phys. Biol. 2, P1-P8. doi:10.1088/1478-3975/2/3/p01

Osawa, M., and Erickson, H. P. (2013). Liposome Division by a Simple Bacterial Division Machinery. Proc. Natl. Acad. Sci. U S A. 110, 11000-11004. doi:10.1073/pnas.1222254110

Pardee, K., Slomovic, S., Nguyen, P. Q., Lee, J. W., Donghia, N., Burrill, D., et al. (2016). Portable, On-Demand Biomolecular Manufacturing. Cell. 167, 248, 259-+. doi: doi:10.1016/j.cell.2016.09.013

Park, N., Um, S. H., Funabashi, H., Xu, J., and Luo, D. (2009). A Cell-free ProteinProducing Gel. Nat. Mater 8, 432-437. doi:10.1038/nmat2419

Prakash, S., and Jones, M. L. (2005). Artificial Cell Therapy: New Strategies for the Therapeutic Delivery of Live Bacteria. J. Biomed. Biotechnol. 2005, 44-56. doi:10.1155/jbb.2005.44

Racker, E., and Stoeckenius, W. (1974). Reconstitution of Purple Membrane Vesicles Catalyzing Light-Driven Proton Uptake and Adenosine Triphosphate Formation. J. Biol. Chem. 249, 662-663. doi:10.1016/s00219258(19)43080-9

Rampioni, G., Mavelli, F., Damiano, L., D’Angelo, F., Messina, M., Leoni, L., et al. (2014). A Synthetic Biology Approach to Bio-Chem-Ict: First Moves towards Chemical Communication between Synthetic and Natural Cells. Nat. Comput. 13, 333-349. doi:10.1007/s11047-014-9425-x
Rasmussen, S., Chen, L., Deamer, D., Krakauer, D. C., Packard, N. H., Stadler, P. F., et al. (2004). Transitions from Nonliving to Living Matter. Science 303, 963-965. doi:10.1126/science.1093669

Richard, P., Pitard, B., and Rigaud, J. L. (1995). Atp Synthesis by the F0f1-Atpase from the Thermophilic bacillus Ps3 Co-reconstituted with Bacteriorhodopsin into Liposomes. Evidence for Stimulation of Atp Synthesis by Atp Bound to a Noncatalytic Binding Site. J. Biol. Chem. 270, 21571-21578. doi:10.1074/ jbc.270.37.21571

Rideau, E., Dimova, R., Schwille, P., Wurm, F. R., and Landfester, K. (2018). Liposomes and Polymersomes: A Comparative Review towards Cell Mimicking. Chem. Soc. Rev. 47, 40. doi:10.1039/c8cs00162f

Rivas, G., and Minton, A. P. (2016). Macromolecular Crowding In Vitro, In Vivo, and in between. Trends Biochem. Sci. 41, 970-981. doi:10.1016/ j.tibs.2016.08.013

Sakamoto, R., Noireaux, V., and Maeda, Y. T. (2018). Anomalous Scaling of Gene Expression in Confined Cell-free Reactions. Sci. Rep. 8, 7364. doi:10.1038/ s41598-018-25532-3

Schmidli, P. K., Schurtenberger, P., and Luisi, P. L. (1991). Liposome-mediated Enzymatic Synthesis of Phosphatidylcholine as an Approach to Self-Replicating Liposomes. J. Am. Chem. Soc. 113, 8127-8130. doi:10.1021/ja00021a043

Schneider, E., and Mangold, M. (2018). Modular Assembling Process of an InSilico Protocell. Biosystems 165, 8-21. doi:10.1016/j.biosystems.2017.12.004

Schwille, P., Spatz, J., Landfester, K., Bodenschatz, E., Herminghaus, S., Sourjik, V., et al. (2018). Maxsynbio: Avenues towards Creating Cells from the Bottom up. Angew. Chem-int Edit. 57, 13382-13392. doi:10.1002/anie.201802288

Shen, Y.-x., Song, W., Barden, D. R., Ren, T., Lang, C., Feroz, H., et al. (2018). Publisher Correction: Achieving High Permeability and Enhanced Selectivity for Angstrom-Scale Separations Using Artificial Water Channel Membranes. Nat. Commun. 9, 3304. doi:10.1038/s41467-018-05447-3

Shimizu, Y., Inoue, A., Tomari, Y., Suzuki, T., Yokogawa, T., Nishikawa, K., et al. (2001). Cell-free Translation Reconstituted with Purified Components. Nat. Biotechnol. 19, 751-755. doi:10.1038/90802

Shimojo, M., Amikura, K., Masuda, K., Kanamori, T., Ueda, T., and Shimizu, Y. (2020). In Vitro reconstitution of functional small ribosomal subunit assembly for comprehensive analysis of ribosomal elements in e. Coli. Commun. Biol. 3, 142. doi:10.1038/s42003-020-0874-8

Shin, J., and Noireaux, V. (2012). An e. Coli cell-free expression toolbox: Application to synthetic gene circuits and artificial cells. ACS Synth. Biol. 1, 29-41. doi:10.1021/sb200016s

Smith, S., Cianci, C., and Grima, R. (2017). Macromolecular Crowding Directs the Motion of Small Molecules inside Cells. J. R. Soc. Interf. 14. doi:10.1098/ rsif.2017.0047

Snead, W. T., Hayden, C. C., Gadok, A. K., Rangamani, P., and Stachowiak, J. (2017). Membrane Fission by Protein Crowding. Proc. Natl. Acad. Sci. U S A. 114, E3258-E3267. doi:10.1073/pnas.1616199114

Sokolova, E., Spruijt, E., and Hansen, M. M. (2013). Enhanced Transcription Rates in Membrane-free Protocells Formed by Coacervation of Cell Lysate. Proc. Natl. Acad. Sci. 110, 11692-11697. doi:10.1073/pnas.1222321110

Sone, N., Takeuchi, Y., Yoshida, M., and Ohno, K. (1977). Formations of Electrochemical Proton Gradient and Adenosine Triphosphate in Proteoliposomes Containing Purified Adenosine Triphosphatase and Bacteriorhodopsin. J. Biochem. 82, 1751-1758. doi:10.1093/ oxfordjournals.jbchem.a131873

Spirin, A. S., Baranov, V. I., Ryabova, L. A., Ovodov, R., Alakhov, Y. B., et al. (1988). A Continuous Cell-free Translation System Capable of Producing Polypeptides in High-Yield. Science 242, 1162-1164. doi:10.1126/science.3055301

Stano, P., and Luisi, P. L. (2010). Achievements and Open Questions in the SelfReproduction of Vesicles and Synthetic Minimal Cells. Chem. Commun. 46, 3639-3653. doi:10.1039/B913997D

Steinkuhler, J., Knorr, R. L., Zhao, Z., Bhatia, T., Bartelt, S. M., Wegner, S., et al. (2020). Controlled Division of Cell-Sized Vesicles by Low Densities of Membrane-Bound Proteins. Nat. Commun. 11, 905. doi:10.1038/s41467-02014696-0

Suzuki, Y., Nagai, K. H., Zinchenko, A., and Hamada, T. (2017). Photoinduced Fusion of Lipid Bilayer Membranes. Langmuir 33, 2671-2676. doi:10.1021/ acs.langmuir.7b00448

Szostak, J. W., Bartel, D. P., and Luisi, P. L. (2001). Synthesizing Life. Nature 409, 387-390. doi:10.1038/35053176 
Tan, C., Saurabh, S., Bruchez, M. P., et al. (2013). Molecular Crowding Shapes Gene Expression in Synthetic Cellular Nanosystems. Nat. Nanotechnol 8, 602-608. doi:10.1038/nnano.2013.132

Tang, T. Y. D., van Swaay, D., deMello, A., and Ross Anderson, J. L. (2015). In Vitro gene Expression within Membrane-free Coacervate Protocells. Chem. Commun. 51, 11429-11432. doi:10.1039/c5cc04220h

Tarryn, E., Miller, T. B., Schwander, Thomas., Diehl, Christoph., Girault, Mathias., McLean, Richard., et al. (2020). Light-powered Co2 Fixation in a Chloroplast Mimic with Natural and Synthetic Parts. Science 368, 649-654. doi:10.1126/ science.aaz6802

Tayar, A. M., Karzbrun, E., Noireaux, V., and Bar-Ziv, R. H. (2015). Propagating Gene Expression Fronts in a One-Dimensional Coupled System of Artificial Cells. Nat. Phys. 11, 1037-1041. doi:10.1038/nphys3469

Tayar, A. M., Karzbrun, E., and Noireaux, V. (2017). Synchrony and Pattern Formation of Coupled Genetic Oscillators on a Chip of Artificial Cells. \%J Proc. Natl. Acad. Sci. 114, 11609-11614. doi:10.1073/pnas.1710620114

Terasawa, H., Nishimura, K., Suzuki, H., Matsuura, T., and Yomo, T. (2012). Coupling of the Fusion and Budding of Giant Phospholipid Vesicles Containing Macromolecules. Proc. Natl. Acad. Sci. U S A. 109, 5942-5947. doi:10.1073/ pnas.1120327109

Thavarajah, W., Silverman, A. D., Verosloff, M. S., Kelley-Loughnane, N., Jewett, M. C., and Lucks, J. B. (2020). Point-of-use Detection of Environmental Fluoride via a Cell-free Riboswitch-Based Biosensor. ACS Synth. Biol. 9, 10-18. doi:10.1021/acssynbio.9b00347

Ugrinic, M., Zambrano, A., Berger, S., Mann, S., Tang, T.-Y. D., and deMello, A. (2018). Microfluidic Formation of Proteinosomes. Chem. Commun. 54, 287-290. doi:10.1039/c7cc08466h

van den Berg, J., Boersma, A. J., and Poolman, B. (2017). Microorganisms Maintain Crowding Homeostasis. Nat. Rev. Microbiol. 15, 309-318. doi:10.1038/ nrmicro.2017.17

van Nies, P., Westerlaken, I., Blanken, D., Salas, M., Mencía, M., and Danelon, C. (2018). Self-replication of DNA by its Encoded Proteins in Liposome-Based Synthetic Cells. Nat. Commun. 9, 1583. doi:10.1038/s41467-018-03926-1

Wang, C., Geng, Y., Sun, Q., Xu, J., and Lu, Y. (2020). A Sustainable and Efficient Artificial Microgel System: Toward Creating a Configurable Synthetic Cell. Small 16, 2002313. doi:10.1002/smll.202002313

Wang, Y.-C., Peterson, S. E., and Loring, J. F. (2014a). Protein post-translational Modifications and Regulation of Pluripotency in Human Stem Cells. Cel Res. 24, 143-160. doi:10.1038/cr.2013.151

Wang, Y. C., Shim, M. S., Levinson, N. S., Sung, H-W., and Xia, Y. (2014b). Stimuliresponsive Materials for Controlled Release of Theranostic Agents. Adv. Funct. Mater. 24, 4206-4220. doi:10.1002/adfm.201400279

Wei, S. P., Qian, Z. G., Hu, C. F., Pan, F., Chen, M-T., Lee, S. Y., et al. (2020). Formation and Functionalization of Membraneless Compartments in escherichia Coli. Nat. Chem. Biol. doi:10.1038/s41589-020-0579-9
Wu, F., and Tan, C. (2014). The Engineering of Artificial Cellular Nanosystems Using Synthetic Biology Approaches. WIREs Nanomed Nanobiotechnol 6, 369-383. doi:10.1002/wnan.1265

Xu, X., Fei, J., Xu, Y., Dong, W., Xue, J., and Li, J. (2021). Boric Acid-Fueled Atp Synthesis by Fo F1 Atp Synthase Reconstituted in a Supramolecular Architecture. Angew. Chem. Int. Ed. Engl. 60, 7617-7620. doi:10.1002/ anie.202016253

Yan, Q., Wang, J., Yin, Y., and Yuan, J. (2013). Breathing Polymersomes: Co2Tuning Membrane Permeability for Size-Selective Release. Separat. React. 52, 5070-5073. doi:10.1002/anie.201300397

Yang, D., Peng, S., Hartman, M. R., Gupton-Campolongo, T., Rice, E. J., Chang, A. K., et al. (2013). Enhanced Transcription and Translation in clay Hydrogel and Implications for Early Life Evolution. Sci. Rep. 3, 3165. doi:10.1038/srep03165

Yavuz, M. S., Cheng, Y., Chen, J., Cobley, C. M., Zhang, Q., Rycenga, M., et al. (2009). Gold Nanocages Covered by Smart Polymers for Controlled Release with Near-Infrared Light. Nat. Mater. 8, 935-939. doi:10.1038/nmat2564

Zhang, Y., Ruder, W. C., and Leduc, P. R. (2008). Artificial Cells: Building Bioinspired Systems Using Small-Scale Biology. Trends Biotechnol. 26, 14-20. doi:10.1016/j.tibtech.2007.09.006

Zhou, X., Wu, H., Cui, M., Nga Lai, S., and Zheng, B. (2018). Long-lived Protein Expression in Hydrogel Particles: Towards Artificial Cells. Chem. Sci. 9, 4275-4279. doi:10.1039/c8sc00383a

Zhu, T. F., and Szostak, J. W. (2009). Coupled Growth and Division of Model Protocell Membranes. J. Am. Chem. Soc. 131, 5705-5713. doi:10.1021/ ja900919c

Zhu, Y., Guo, X., Liu, J., Li, F., and Yang, D. (2020). Emerging Advances of Cell-free Systems toward Artificial Cells. Small Methods 4, 2000406. doi:10.1002/ smtd.202000406

Conflict of Interest: The authors declare that the research was conducted in the absence of any commercial or financial relationships that could be construed as a potential conflict of interest.

Publisher's Note: All claims expressed in this article are solely those of the authors and do not necessarily represent those of their affiliated organizations, or those of the publisher, the editors and the reviewers. Any product that may be evaluated in this article, or claim that may be made by its manufacturer, is not guaranteed or endorsed by the publisher.

Copyright (c) 2021 Wang, Yang and Lu. This is an open-access article distributed under the terms of the Creative Commons Attribution License (CC BY). The use, distribution or reproduction in other forums is permitted, provided the original author(s) and the copyright owner(s) are credited and that the original publication in this journal is cited, in accordance with accepted academic practice. No use, distribution or reproduction is permitted which does not comply with these terms. 